\title{
O sujeito do conhecimento - o objeto da ação: a "passagem", identidade e diferença na filosofia de Arthur Schopenhauer
}

\author{
$\frac{\text { MARGIT RUfFING }}{\text { Johannes Gutenberg Universität - Mainz }}$
}

Resumo: No presente texto, buscarei levar a sério as tensões ou mesmo contradições da filosofia de Schopenhauer e tentarei compreendê-las ao invés de censurar o filósofo por irracionalidade ou inconsequência. A primeira parte do texto analisa a teoria do conhecimento de Schopenhauer sob os aspectos $\mathrm{da}$ diferença e da passagem, e a segunda investiga o liame entre a ética e a estética buscando uma resposta para a questão da identidade presente na determinação da compaixão como expressão do conhecimento da unidade da vontade.

Palavras-chave: conhecimento, ação, identidade, diferença, passagem.
Abstract: In the present text, I'll dwell upon the tensions or contradictions in the philosophy of Schopenhauer, and I'll try to understand them instead of accusing the philosopher of irrationality or inconsequence. The first part of the text investigates Schopenhauer's theory of knowledge under the aspects of difference and passage, and the second part investigates the liason between etchis and aesthetics searching for an answer for the question of the present identity in the determination of compassion as an expression of the knowledge of the unity of the will.

Keywords: knowledge, action, identify, difference, passage.

A verdadeira pesquisa acadêmica universitária da filosofia de Schopenhauer não tem mais do que um quarto de século; Rudolf Malter foi o primeiro que considerou o sistema schopenhaueriano como um derivado da filosofia transcendental. Sua monografia sobre o transcendentalismo de Schopenhauer, de 1991르, assim como sua pequena introdução à obra do pensador,

1. Malter, R. Arthur Schopenhauer. Transzendentalphilosophie und Metaphysik des Willens. Stuttgart-Bad Cannstatt: Frommann-holzboog, 1991. 
Der eine Gedanke $e^{2}$, apresentam uma interpretação convincente da metafísica da vontade, pondo em relevo a conexão entre a teoria do conhecimento e a ética da compaixão como soteriologia. Buscarei continuar a tradição fundada por Malter, uma tradição de pensadores que levam a sério as tensões ou mesmo as contradições da filosofia de Schopenhauer, e que buscam compreendê-las ao invés de censurá-lo por irracionalidade ou inconseqüência.

Esta é a razão por que escolhi os termos "passagem", "identidade" e "diferença" para caracterizar a estrutura extremamente dualista do sistema, por assim dizer ambígua, mas não necessariamente contraditória, que deriva do fato de que Schopenhauer define a coisa em si afirmativamente. Ao contrário de Kant, Schopenhauer não renuncia a definir o conhecimento do essencial a que - segundo ele - a consciência humana não tem nenhum acesso racional. Embora a vontade, essência do mundo, só exista em suas aparências, como representação, é possível, segundo Schopenhauer, adquirir um saber não-representativo que atravessa ou transcende a aparência. Por um lado, este pensamento filosófico reclama a identidade indissolúvel do essencial e da aparência no plano metafísico, e ao mesmo tempo, por outro lado, a realidade do sofrimento na existência humana só se explica pela divergência fundamental do princípio do querer e suas objetivações, pelas quais somente o princípio pode ser reconhecido. A questão da diferença põe-se em relação à essência - a vontade - e à aparência - as representações - assim como em relação às próprias faculdades de conhecimento, no interior das representações. Mas: só há um mundo! A identidade do diverso permanece, portanto, uma estrutura principal do sistema. O conceito de "passagem", no sentido de "transição", parece-me apto para explicar a necessidade de uma crítica da razão, por assim dizer; pois é difícil ver como se dá a conexão da parte querente com a parte cognoscente da consciência humana se se aceita a teoria epistemológica de Schopenhauer, que não prevê nenhuma permeabilidade entre as faculdades de conhecimento.

2. Malter, R.Der eine Gedanke. Hinführung zur Philosophie Arthur Schopenhauers. Darmstadt: Wissenschaftliche Buchgesellschaft, 1988. 
O próprio Schopenhauer não fala jamais de passagem no plano estrutural e formal, assim como evita a terminologia distinta de "diferença" e "identidade". Assim, o título da obra capital $O$ mundo como vontade e representação evidentemente descreve, para nós, a estrutura dualista que caracteriza todo o sistema, enquanto, segundo Schopenhauer, esse título exprime a unidade essencial do ser e suas aparências - a verdade mesma. Como elementos estruturais e formais da reflexão schopenhaueriana, os aspectos da diferença, da identidade e da passagem - como figuras do pensamento - são aptos a explicar uma teoria da consciência baseada sobre o caráter sistemático d'O mundo como vontade e representação. Neste contexto, o terceiro livro da obra capital, a estética da contemplação, desempenha um papel chave.

$\mathrm{Na}$ primeira parte do texto, portanto, eu gostaria de falar da teoria do conhecimento, à qual pertence o conhecimento das idéias, sob os aspectos da diferença e da passagem. O liame inerente entre a estética e a ética na filosofia de Schopenhauer, em uma segunda parte, dá ensejo a buscar uma resposta à questão: "Como é possível o conhecimento da identidade?” no domínio ético. Pois esta questão é de uma importância extraordinária no que diz respeito ao plano da filosofia prática de Schopenhauer, que considera a compaixão como possibilidade da moralidade do homem - a compaixão como expressão do conhecimento da identidade.

\section{O problema da diferença e a "passagem" na teoria do conhecimento de Schopenhauer.}

Eu gostaria de começar minhas considerações com uma citação pela qual nos colocamos imediatamente no coração da filosofia de Schopenhauer:

A verdade é que os dados imediatos de nossa consciência compreendem uma existência subjetiva e uma existência objetiva, o que é em si e que só é do ponto de vista de outro, um sentimento de nosso próprio eu [moi] e um sentimento de outra coisa, e estes dados se apresentam a nós como sendo tão radicalmente distintos que nehuma outra diferença poderia ser comparada àquela. Cada um conhece imediatamente a si-mesmo, e de todo 
o resto só tem um conhecimento mediato. Eis o fato; eis também o problema. ${ }^{3}$

Esta citação ajuda a esclarecer a oposição que existe entre os aspectos do outro e do mesmo em Schopenhauer, oposição chamada por ele mesmo de "problema" ou ainda "fato". Este substantivo francês, o fait [fato], exprime melhor que a palavra alemã (Tatsache) que se trata de uma coisa que éfeita: esta diferença não é somente um fato de consciência, mas é feita pela consciência ou, mais exatamente, pela consciência intelectual. É uma diferença tal como dada originalmente na consciência humana, porque feita por nosso conhecimento: conforme o texto citado, o conhecimento de si é imediato, enquanto o conhecimento do outro é mediato. Mas a diferença entre a existência subjetiva e a existência objetiva, entre a consciência de si e a consciência de outras coisas, esta diferença é, para Schopenhauer, apenas uma parte da verdade: pois, sobre o plano metafísico, só há "o um", e este ser único, a essência de tudo, é a vontade de viver, o querer-viver.

Schopenhauer está convencido de que cada indivíduo que tem a capacidade de raciocinar se rende à evidência, seja por consideração empírica, seja por reflexão profunda, de que há uma entidade única, interna e comum a todos os fenômenos. Mas o que antes nos parece claro e evidente não é a entidade interna - ao contrário, é o mundo exterior, as coisas fora de nós mesmos, os objetos no espaço. Que as coisas mais afastadas da realidade essencial pareçam as mais próximas do conhecimento é um erro humano. A razão deste erro está na natureza de nosso conhecimento, precisamente na decomposição da representação do sujeito e do objeto. Em outros termos, reconhecer significa ser sujeito para um objeto e ser objeto para um sujeito; em caso de conhecimento, existe sempre um cognoscente e um conhecido, o cognoscente não sendo jamais capaz de se conhecer a si mesmo. A natureza imediata de nossa intuição, a claridade da reflexão, em suma, a evidência intelectual nos parece exprimir a realidade: acreditamos reconhecer as

3. Schopenhauer, A. Le monde comme volonté et comme représentation. Trad. de A. Burdeau. Paris: PUF, 1966, capítulo 18 dos Suplementos, "Comment la chose en soi est connaissable” [Como a coisa em si é cognoscível], p. 886. 
coisas como elas são, as coisas-em-si. Segundo Schopenhauer, este é o caráter natural da representação: o senso comum, assim como o pensamento científico, só é capaz de reconhecer a pluralidade (Vielheit), isto é, a diversidade, e de notar um encadeamento de relações causais - o "véu de Maia", o mundo como representação. Pois, conforme a teoria do conhecimento de Schopenhauer, é o entendimento que constrói de um só golpe o mundo, ligando coisas singulares como causas e efeitos. É portanto o intelecto, as faculdades do entendimento e da razão reflexionante, que criam a diferença. Eles respondem à questão "por que", mas não compreendem "o quê" do mundo - como diz Schopenhauer.

Segundo ele, o intelecto e a razão têm funções claramente distintas e evidentemente definidas: o entedimento (Verstand) é a faculdade de intuição (Anschaunng) que conhece a causalidade; a razão (Vernunft), como faculdade de reflexão, produz os conceitos (Begriffe) para "conservar" o conteúdo do conhecimento intuitivo. Apesar da diferença entre a função intuitiva e a função conceitual dos modos de conhecimento, há entre elas algo comum: o entendimento, assim como a razão, criam apenas uma representação do mundo - dominada pelo princípio de razão, dividida em sujeito e objeto. O sujeito cognoscente e ativo apresenta e representa as coisas singulares, compõe-nas no mundo encadeando-as como causa e efeito. $\mathrm{O}$ resultado da atividade dessas funções intelectuais é o que chamamos de realidade - em alemão Wirklichkeit (Wirkung (efeito)!) -, o que representamos na intuição do entendimento e na reflexão da razão como "encadeamento" de relações espaciais e temporais, o que quer dizer representar ou conhecer.

A meu ver, essas faculdades analiticamente separáveis que formam a consciência intelectual não devem ser consideradas como desempenhando uma única função, mesmo quando Schopenhauer diz rigorosamente que o conhecimento da causalidade seria a única função do entendimento. ${ }^{4}$ Ao contrário, é preciso observar a complexidade dessas faculdades - em correlação com a causalidade do

4. Cf. Schopenhauer, A. Die Welt als Wille und Vorstellung. Vol. I, §4. In: Sämtliche Werke. Org. de Arthur Hübscher. Wiesbaden: Brockhaus, 1972, vol. II, pág. 13. 
lado do objeto - para explicar o pensamento único de que o mundo é autoconhecimento da vontade. A frase schopenhaueriana "Die Welt ist Selbsterkenntnis des Willens" "O mundo é auto-conhecimento da vontade") $)^{5}$ enuncia o que significa "ser vivente" - a tomada de consciência de si, de si mesmo, pelo querer viver não consciente. É o acontecimento complexo do autoconhecimento do não consciente através do mundo da representação disfarçada que leva Schopenhauer a comparar seu sistema a um organismo vivo, no qual cada parte contribui para o fim do todo. Mas lá, onde não se pode falar de complexidade, é preciso falar também de passagens, o que eu gostaria de analisar agora de forma mais nuançada.

O objetivo final da consciência intelectual - que é ao mesmo tempo o dever da filosofia - é, segundo Schopenhauer, o conhecimento essencial do mundo, cujo ponto de partida é tomado necessariamente da representação, portanto dos objetos da experiência. É a intuição que é "competente" para o conhecimento dos objetos; o conhecimento abstrato, ao qual não corresponde nenhum objeto real ou, mais exatamente, ao qual não corresponde mais objeto real, este conhecimento é a tarefa da razão. A imediação poderia ser considerada, enquanto modo de certeza por si mesmo, o critério da qualidade do conhecimento: ela indica a congruência da experiência ao conceito. A imediação é um traço característico do conhecimento pelo entendimento intuitivo. A intuição se apresenta como garantia de si mesma, segundo as palavras de Schopenhauer.

Até aqui, há duas perspectivas de passagem: 1) há uma passagem na composição do conhecimento objetivo; e 2) há uma outra no interior da consciência subjetiva. $\mathrm{O}$ que isso significa?

Ad 1) Segundo Schopenhauer, o entendimento é o correlato subjetivo da matéria, e a própria matéria é o equivalente da causalidade. $\mathrm{O}$ entendimento e a causalidade são, portanto, o aspecto subjetivo e o aspecto objetivo de uma representação definida por eles.

5. Cf. Schopenhauer, A. Die Welt als Wille und Vorstellung. Vol. I, §71. In: Sämtliche Werke, vol. II, pág. 485; e Idem, Vol I, "Crítica da filosofia kantiana”. In: Sämtliche Werke, vol. II, pág. 506. 
Poder-se-ia interpretar a identificação do entendimento e da matéria de modo que Schopenhauer preparasse sua metafísica de uma vontade compreendida como essência que se corporifica, que só existe materialmente objetivada. Este projeto filosófico, a explicação do conhecimento metafísico, dá lugar a uma concepção de intuição de uma importância extraordinária para o sistema inteiro. A intuição se baseia sobre a apercepção sensual, e esta é condicionada pelo que Schopenhauer nomeia "Empfindung" (sensação), a qual contém a determinação total do objeto como impressão integrante. A intuição é a retomada da sensação precedente no presente, sua re-presentação, isto é, a representação do conteúdo sensual na consciência, e eis aí a primeira tomada de consciência de si do sujeito pelo objeto. - Ao mesmo tempo, a intuição constitui o fundamento dos conceitos abstratos, mas o conhecimento abstrato e conceitual do objeto não é mais imediato, e portanto menos certo. É uma conseqüência evidente que, segundo Schopenhauer, a razão - em virtude de sua falta de imediatez - é, por assim dizer, de qualidade secundária; sua função criadora e produtora é necessariamente religada à intuição e dela depende.

Resumamos este primeiro aspecto da passagem ou transição: o entendimento, competente para conhecer o objeto concreto como ele nos é dado aos sentidos, torna possível a passagem do desconhecido ou do que não é ainda conhecido à consciência: a sensação sem consciência (o termo "inconsciente" é antes utilizado pela psicanálise) corresponde à unidade hermética do objeto, mas pertence ao sujeito, no qual o entendimento forma ativamente a intuição. (A sensação e a intuição só diferem uma da outra teoricamente, formando uma unidade na realização da consciência). A dependência da intuição e a perda da imediatez tornam a razão falha e exposta a erros. Mas, também segundo Schopenhauer, é a razão que torna possível o conhecimento filosófico, produzindo os conceitos abstratos de que a filosofia tem necessidade. Isso significa que a razão deve ter um acesso ao essencial através do mundo representativo, que consideramos ser a realidade porque o entendimento a constitui como totalidade de relaçãoes causais. Este acesso da razão ao conhecimento da essência nos leva ao segundo aspecto. 
Ad 2) A segunda passagem, no interior da consciência subjetiva, encontra-se na consciência de si mesmo. Segundo Schopenhauer, a consciência de si significa a "percepção do sentido interior" por contraste à percepção do mundo exterior pelo entendimento. Mas é somente a conexão do conhecimento exterior e do conhecimento interior que torna possível "a compreensão da natureza e de si mesmo". ${ }^{6}$ Trata-se aqui, portanto, da conexão entre a vontade e o conhecimento cujo conjunto é o que se chama consciência de si. Esta consiste no conhecimento dos movimentos não figurativos da vontade pela reflexão, isto é, a faculdade da razão referindo-se às afecções da vontade na consciência de si - refletindo-as, definido-as, concebendo-as. É justamente o conhecimento abstrato que dá acesso aos conteúdos não figurativos da consciência volitiva.

$\mathrm{O} \S 11$ do primeiro livro de $O$ mundo como vontade e representação poderia servir para esclarecer essa performance racional de síntese. De modo um tanto surpreendente, no contexto de suas explicações sobre a faculdade da razão, cuja expressão é o saber (§19), Schopenhauer fala do sentimento (Gefübl). Segundo suas explicações, a razão deveria ser capaz de conceber os conteúdos apenas sentidos da consciência, isto é, de encontrar para eles conceitos apropriados. Pois Schopenhauer diz: caso a razão não tenha conseguido ainda, nem de modo algum consiga conceber um conteúdo volitivo, ela aplica a ele o conceito indefindo de "sentimento". Eu gostaria de interpretar este parágrafo de maneira que se tenha de supor que: 1 . a razão tem um acesso direto aos conteúdos ou processos irracionais, produzidos pela afecção da vontade, e 2 . a razão é capaz de transformá-los em saber. Por outro lado, é a razão, e não o entendimento - neste caso ignorado, por assim dizer, pela razão -, que nos torna capazes de conceber os sentimentos. Isso demonstra a permeabilidade (Durchlässigkeit) e a dinâmica do querer e do conhecer: algo que uma teoria do conhecimento deve prever para poder explicar a conexão da faculdade racional com a consciência de si irracional e sentida.

6. Schopenhauer, A. Über den Willen in der Natur, Phys. Astronomie ("Sobre a vontade na natureza, Astronomia física"). In: p. 91. . Sämtliche Werke, vol.IV, 
No contexto da segunda parte da epistemologia schopenhaueriana - no terceiro livro, sobre as representações independentes do princípio de razão suficiente - é preciso falar do caráter de conhecimento da arte, portanto do conhecimento representativo por intuição das idéias. O conhecimento intuitivo do entendimento leva normalmente ao saber do mundo mais ou menos abstrato, mais ou menos científico, mas ele permanece sempre ligado à compreensão e à aplicação do princípio causal. Isso quer dizer que ele permanece dependente e relativo - e, assim, não é apropriado a compreender verdadeiramente a significação do mundo e da vida humana. É isso que o distingue da representação "independente do princípio de razão suficiente", cuja possibilidade e realidade são demonstradas pela contemplação estética, como Schopenhauer expõe no terceiro livro de sua obra capital.

A razão desempenha um papel significativo também no contexto do conhecimento das idéias: em minha opinião, a contemplação estética, como modo de conhecimento cujo objeto é a idéia, é o nó central de transição, por assim dizer, do sistema schopenhaueriano. A percepção das idéias necessita - como percepção da essência metafísica - da suposição do caráter unificador das faculdades de conhecer, comportando uma autarquia relativa da razão.

Falando da faculdade de representação independente das relações causais, Schopenhauer utiliza, no contexto da estética, o termo menschilcher Intellekt [intelecto humano], servindo a palavra Intellekt, como sinônimo de Verstand (entendimento), para assinalar seu caráter intuitivo. $\mathrm{O}$ adjetivo menschlich, humano, assinala a diferença em relação aos animais, que - segundo Schopenhauer - também são dotados de entendimento ou intelecto. Esta diferença consiste então na intelectualidade humana específica: sua racionalidade, como condição da ponderação (Besonnenheit). A capacidade humana de ponderação é o que importa: uma situação mental indispensável para o conhecimento filosófico, assim como para o ato moral. (Voltarei a isso mais adiante.)

É o "intelecto humano" que produz o conhecimento extraordinário da contemplação estética. Ele poderia sobrepujar a ligação com a relacionalidade causal para transcender a uma compreensão 
do mundo não limitada por relações espaço-temporais, um conhecimento universal que parte do objeto mas chega a si mesmo. Pois a idéia é mais que um objeto concreto: ela torna possível a compreensão da própria vontade na medida em que é sua "objetidade adequada” (adäquate Objektität). A determinação (definição perfeita, durchgängige Bestimmung) do objeto contemplado se chama "ideal" porque o sujeito que contempla engendra uma representação "objetiva", isto é, uma representação de valor universal e incondicionada. Este acontecimento mental é o que Schopenhauer entende por "contemplação estética".

O conhecimento das idéias é definido, portanto, pela maior proximidade possível ao objeto e pela maior distância possível do sujeito em relação à Vontade. A contemplação estética pode ser apreendida como um processo, como condição mental e como modo de conhecimento, em todo caso como racionalidade que não se limita a conceitos, mas os transcende (... a significação de "ponderação" no plano epistemológico).

O caráter transitório do conhecimento estético aparece nessa transcendência que se manifesta como "transformação no sujeito". A consciência de si ultrapassa a separação entre sujeito e objeto, suportando a tensão entre a proximidade e a distância do conhecimento ao querer. A contemplação é, por assim dizer, a consciência de uma intensidade extraordinária da identidade no mundo da representação alienada. Ela é criada pelo objeto ideal, portanto pela vontade idealmente objetivada, e por sua presença na consciência humana, uma presença - dito metaforicamente - energética.

A concepção da idéia compreende dois aspectos como unidade: é preciso pensá-la como se o sujeito cognoscente pudesse adotar o ponto de vista da Vontade - apesar do caráter exclusivo da consciência de si refletida e volitiva. Schopenhauer define a idéia, por um lado, como jede bestimmte und feste Stufe der Objektivation des Willens [cada grau determinado e fixo da objetivação da Vontade $]^{7}$, por outro como die unmittelbare Objektität des Willens

7. Cf. Schopenhauer, A. Die Welt als Wille und Vorstellung. Vol. I, §25. In: Sämtliche Werke, vol. II, pág. 154. 
auf einer bestimmten Stufe [a objetidade imediata da Vontade em um determinado grau]. ${ }^{8}$ Notemos a mudança do ponto de vista! A expressão "objetidade da vontade em um determinado grau" pode ser interpretada como realização da fenomenalidade potencial da vontade, de maneira mais ou menos intensiva, no fato de sua objetivação. Do ponto de vista das objetivações (às quais nós mesmos, seres humanos, pertencemos), encontra-se, correspondente a seus graus, uma gradação de consciência, e isso significa uma gradação de autoconhecimento e autoconsciência da vontade correpondente à gradação de acessibilidade do saber ao "quê do mundo" por meio das objetivações.

Para concluir esta parte do texto, explicarei ainda uma vez, de maneira resumida, a posição da idéia. Em relação à temática da transição, a idéia tem uma dupla função: ela indica a passagem da coisa em si à aparência, assim como a passagem da intuição do intelecto (Verstand), ligado às relações causais, à intuição ideal, que faz com que o "intelecto humano" apreenda o universal e o essencial na aparição singular. Consequentemente, a idéia se distingue das outras representações por seu caráter transitório: ela indica a única possibilidade de transcender a representação - separando-se dela sem, ao mesmo tempo, abandoná-la - para adquirir um saber essencial do mundo e de nossa existência nele. A consciência estética extremamente intensiva, mas instável, encontra-se no topo da gradação hierárquica da objetividade da Vontade. A consciência estética pertence apenas ao "intelecto humano", potencialmente genérico e universal, mas apenas realizável enquanto sujeito puro do conhecimento. A idéia de indivíduo significa assim o conhecimento de si da vontade, que se realiza originariamente como contemplação estética antes de poder ser refletida filosoficamente. "Originariamente" quer dizer aqui o mesmo que "a priori", i.e. antes de toda aparição, pois a idéia participa da vida essencial ao aderir à Vontade como sua forma, condicionando a realização de suas conformações (Objektivationen, "objetivaçôes") como sua formabilidade (Objektität, "objetidade"). Ao mesmo tempo, a idéia está em

8. Cf. Schopenhauer, A. Die Welt als Wille und Vorstellung. Vol. I, §34. In: Sämtliche Werke, vol. II, pág. 210. 
conexão com a razão: nos manuscritos (HN) encontra-se uma pequena frase que indica esta conexão da idéia à razão, a idéia sendo descrita como "fantasma em presença da razão" que seria preciso apreender não como força natural, mas como força que produziria efeitos não causais na natureza - uma expressão contraditória ou mística -, uma força que Schopenhauer chamaria "mágica", como ele mesmo diz, se esta terminologia fosse filosoficamente correta. ${ }^{10}$ A independência da idéia face ao princípio de razão suficiente, isto é, à causalidade, faz com que a idéia se afaste do intelecto (da faculdade da causalidade) e se aproxime da "presença da razão", uma razão que é capaz de superar ou transcender a realidade dada pelo intelecto como o demonstra, por exemplo, sua capacidade de conceber sentimentos.

A compreensão de si mesmo não se faz pelo intelecto, mas "do interior": ela nos chega. A partir disso, esta compreensão consiste em reconhecer a identidade da vontade e do corpo humano, chamado objetividade imediata. Segundo Schopenhauer, este saber da identidade da vontade e do corpo humano é a "verdade filosófica", pois a compreensão de si mesmo é ao mesmo tempo a compreensão da vontade como a entidade essencial do mundo, a chave da explicação metafísica da vida que transcende do conhecimento in concreto ao conhecimento in abstracto - com a ajuda da razão.

Vimos agora que e como a concepção de idéia desempenha um papel excepcional na metafísica da vontade: ela marca o conhecimento da passagem, do processo de objetivação da vontade, de sua aparição (se bem que os termos "passagem" e "processo" exprimem a temporalidade e a espacialidade, sobre as quais é incorreto falar quando há referência à vontade). No discurso filosófico, onde a diferenciação predomina, a arte como modo de conhecimento forma uma exceção. Segundo Schopenhauer, na contemplação estética o homem esquece seu caráter de vontade - e todas

9. Schopenhauer, A. Der Handschriftliche Nachlaß in fünf Bänden. Vol I. Org. de Arthur Hübscher. München: DTV, 1985, p. 130 e ss. O fragmento indicado, na p. 130 , é o no 226.

10. Cf. idem, ibidem. 
as conseqüências deste caráter: o sofrimento em todas as suas facetas. Entretanto, é um conhecimento essencial que tem lugar na contemplação estética: a compreensão das idéias como as únicas objetivações adequadas da vontade. Em outros termos, é pela contemplação de belos objetos de arte ou de objetos sublimes da natureza que o homem compreende na prática que o conhecimento pode dominar a vontade. Ainda que a situação da contemplação seja limitada - ela não pode ser iniciada ou prolongada intencionalmente -, ela é de uma importância fundamental no que diz respeito à teoria do conhecimento schopenhaueriana: a vontade é a mais afastada, porque é esquecida, rejeitada pelo conhecimento, mas é ao mesmo tempo a mais próxima, porque é compreendida em suas relações ideais, objetivada de maneira adequada nas idéias que conservam o caráter intemporal e não espacial da vontade. Trata-se, portanto, de uma forma de conhecimento intelectual do entendimento que produz intuições. Mas este conhecimento estético, a intuição ideal, é liberado da relatividade causal, por um lado pela idealidade do objeto, por outro pela faculdade do entendimento de esquecer a predominância da vontade.

Entretanto - posta de lado a diferença -, no conhecimento imediato de si mesmo o homem faz a experiência de sua identidade essencial. Esta experiência é a condição do ato moral, que Schopenhauer analisa como fato empírico, demonstrando uma moralidade humana dependente do conhecimento sem que o homem tivesse a potência de provocá-la conscientemente. Isso abre a questão da segunda parte, que nos leva ao plano da filosofia prática, da ética da compaixão explicada por Schopenhauer no quarto livro de sua obra capital.

\section{Como é possível o conhecimento da identidade?}

A duplicidade da vontade e do conhecimento ressurge claramente na frase seguinte de Schopenhauer. É assim que "O mundo é consciência/conhecimento de si mesmo da vontade". Além disso, encontra-se aqui a determinação do mundo de maneira comprimida, como conhecimento e como vontade. Estes últimos são postos em relação, tomados em conjunto e não apenas como adição ("o mundo como representação $e$ como vontade"). O co- 
nhecimento de si mesmo da vontade significa que há a possibilidade da vontade consciente - no ou pelo ser humano. A vontade, caracterizada como cega, portanto não consciente, pode ser compreendida por uma de suas objetivações, o que significa que ela se reconhece a si mesma. De maneira mais concreta: o homem tem a consciência de si mesmo como ser volitivo e ser que reconhece. $\mathrm{O}$ conhecimento de si mesmo é imediato, sem fazer a distinção entre sujeito e objeto; entretanto, trata-se apenas de um saber. Visto que representar quer dizer reconhecer, segundo Schopenhauer, o saber imediato de si mesmo não pode ser um conhecimento com o caráter de representação, mas um conhecimento toto genere diverso. Como ele é possível? Só se pode constatar que ele está presente como um dado da consciência. No começo do segundo livro de $O$ mundo como vontade e representação, Schopenhauer escreve que "a chave do enigma está dada ao sujeito do conhecimento, manifesto como indivíduo". Esta chave é a Wille [vontade]. O homem compreende a significação de sua individualidade da seguinte forma: cada atividade do corpo é expressão da própria vontade. Portanto, é a corporalidade que contém o conhecimento da vontade. ${ }^{11}$ Dito de outro modo, o ser individual não é a coisa em si, mas a coisa em si se realiza sob a forma da individualidade (pelo corpo, que existe apenas individualmente).

Assim como o querer viver é o princípio fundamental da metafísica, ele é também o princípio da existência humana: no caso da objetivação da vontade no ser humano, há a diferença entre a vontade não consciente e sua própria representação consciente; no presente caso, a coisa em si, o princípio único, torna-se indivíduo já no plano das idéias. O resultado é um ponto de vista extraordinário: a individuação como perda da identidade! A alienação essencial consiste, portanto, no fato de que a entidade única se realiza pela individuação. Schopenhauer utiliza também o termo Selbstentzweiung da vontade: a desunião de si mesma.

11. Cf. Schopenhauer, A. Die Welt als Wille und Vorstellung. Vol. I, §18. In: Sämtliche Werke, vol. II, pág. 120: "a vontade é o conhecimento a priori do corpo, e o corpo o conhecimento a posteriori da vontade". 
A perda de identidade da vontade revela a explicação metafísica do sofrimento que é característico da existência humana, a vida mesma. Por outro lado, a consciência, que considera a diversidade e a multiplicidade das coisas como sendo a entidade verdadeira, aumenta esse sofrimento existencial. Isto é: as aspirações, os desejos, as carências da vida, consistem na impossibilidade de satisfação. É a condição humana fundada sobre a verdade metafísica: a vontade não se reconhece nas suas próprias aparências ou, em outros termos, ela domina o conhecimento determinando-o e utilizando-o para seus próprios interesses. A razão e suas funções estão sob as ordens da vontade, elas são instrumentalizadas. $O$ erro da razão, sua tendência de superestimar-se ao tomar-se pela totalidade da realidade, são as causas principais do sofrimento da vida.

Segundo Schopenhauer, porém, o conhecimento intelectual subordinado à vontade implica a possibilidade de liberar-se e voltar-se contra a vontade, reconhecendo-a e compreedendo-a como fonte de sofrimento. Esta postura do conhecimento diante da vontade é apenas uma postura da vontade diante de si mesma, a que Schopenhauer também chama supressão (Aufhebung) da desunião ou alienação da vontade consigo mesma. A supressão da desunião significa apenas a compreensão da vanidade do principium individuationis, o princípio que causa a diferença das aparências. Paradoxalmente, o saber da vanidade da individualidade se dá apenas na consciência do indivíduo humano, na medida em que o conhecimento humano de si mesmo é a origem da verdade metafísica sobre a relação entre a vontade e o conhecimento. Portanto, é preciso que a filosofia, precisamente a metafísica schopenhaueriana, explique a relação entre a identidade sentida e a diferença reconhecida abstratamente, fazendo a distinção entre o essencial e o não-essencial. Como sabemos, porém, a verdade filosófica não é, segundo Schopenhauer, produzida originariamente pelo intelecto, ela é antes dada como sentimento de identidade. $\mathrm{Na}$ contemplação estética ela se mostra sob a forma de intuição ideal. No plano da filosofia moral, a verdade filosófica da identidade metafísica se mostra como compaixão. No quarto livro de $O$ mundo como vontade e representação e em Sobre o fundamento da moral, Schopenhauer apresenta a descrição do fenômeno da com- 
paixão para afirmar sua metafísica da vontade por meio de uma teoria moral que atinge seu ponto culminante com a doutrina da negação da vontade. A existência da compaixão é um fato empírico, inexplicável e, além disso, qualificado por Schopenhauer como "misterioso". A compaixão não é, portanto, uma conseqüência ou conclusão do conhecimento filosófico, mas antes, por assim dizer, seu outro lado. Ali onde se dá a compreensão de si mesmo, como ser substancialmente idêntico ao outro, está a compaixão, que não pode ser nem apreendida nem estudada, mas é, ao contrário, um fenômeno natural, dado imediatamente na consciência humana assim como a compreensão adequada de si mesma. O conhecimento de que a individuação não é real, mas, ao contrário, imaginária, "a esta verdade o sânscrito deu a fórmula definitiva: tat twan asi, você é isto, ela salta aos olhos sob a forma da compaixão". ${ }^{12}$ Assim, "meu ser interior, verdadeiro, também está no fundo de tudo o que vive". ${ }^{13}$ No fundo da consciência humana existe a certeza de que, além de toda pluralidade e diversidade dos indivíduos, sua unidade existe verdadeira e realmente. Vivendo esta certeza, o homem compreende que a diferença do mesmo em relação ao outro não é absoluta, que o mundo exterior do mesmo é homogêneo à própria substância: "Os outros não são para ele um não-eu, mas ele diz deles: ainda sou eu". ${ }^{14}$ É o que diz o homem que tem conhecimento da vanidade do principium individuationis.

$\mathrm{O}$ aspecto positivo da perda de individualidade é, portanto, a superação do egoísmo, sem a qual nenhuma compaixão pode ter lugar. O sentimento que melhor exprime a atitude de compaixão torna possível a percepção da identidade na diferença: esse sentimento é o amor ao próximo.

12. Schopenhauer, A. Le fondement de la morale. Trad. de A. Burdeau. Paris: Aubier Montaigne, 1978, §22, p. 190. (Em português: Schopenhauer, A. Sobre o fundamento da moral. Trad. de Maria Lúcia Cacciola. São Paulo: Martins Fontes, 1995, p. 208.) "Pitie" foi o termo escolhido, na tradução francesa citada pela autora, para verter a palavra "Mitleid" (compaixão) do original alemão.

13. Idem, ibidem.

14. Schopenhauer, A. Le fondement de la morale, §22, p. 191. (Em português: Schopenhauer, A. Sobre ofundamento da moral, p. 209.) 
Para concluir, a consideração da metafísica da vontade schopenhaueriana em termos de identidade e diferença exprime claramente que a estrutura dualista se encontra já na base do pensamento filosófico. Aí está a explicação do princípio vital como vontade não-consciente objetivando-se no seio dos seres conscientes. A perda de identidade é também dupla: o princípio único se apresenta como diverso conforme o principium individuationis, isto é, sob a forma do espaço e do tempo; e o conhecimento precisa da separação sujeito-objeto, seguindo necessariamente o princípio de razão suficiente. Segundo Schopenhauer, porém, a vida prática demonstra que a diferença dolorosa pode ser sobrepujada pela compreensão da vanidade da individualidade, enfim pela compaixão, que é a expressão da "bondade do coração" (Güte des Herzens) do caráter bom - e assim, nos termos de Schopenhauer, o "princípio unificante". Permitam-me terminar com uma bela citação, aparentemente apta a constituir um fim em um duplo sentido:

(...) o intelecto é um princípio de diferenciação, consequentemente de separação. Suas variedades diversas (...) dão a cada um outros conceitos, graças a que cada um vive de algum modo no mundo, onde ele só se encontra com seus iguais; os outros ele apenas pode chamar de longe e tentar se fazer compreender entre eles.

Grandes diferenças no grau de inteligência e no desenvolvimento intelectual abrem um grande abismo entre os homens; somente a bondade do coração pode transpô-lo, e é ela que é o princípio unificante que identifica os outros com nosso próprio eu. ${ }^{15}$

\section{Bibliografia}

MALTER, R. Der eine Gedanke. Hinfübrung zur Philosophie Arthur Schopenhauers. Darmstadt: Wissenschaftliche Buchgesellschaft, 1988.

15. Schopenhauer, A. Le monde comme volonté et comme representation, capítulo 15 dos suplementos, "Das imperfeiçôes essenciais de nosso intelecto", p. 835. 
- Arthur Schopenhauer. Transzendentalphilosophie und Metaphysik des Willens. Stuttgart-Bad Cannstatt: Frommann-holzboog, 1991.

SCHOPENHAUER, A. Le monde comme volonté et comme représentation. Trad. de A. Burdeau. Paris: PUF, 1966.

.Sämtliche Werke. Org. de Arthur Hübscher.Wiesbaden: Brockhaus, 1972. 7 vols.

Le fondement de la morale. Trad. de A. Burdeau. Paris: Aubier Montaigne, 1978.

Der Handschriftliche Nachlaß in fünf Bänden. Org. de Arthur Hübscher. München: DTV, 1985. 5 vols.

. Sobre o fundamento da moral. Trad. de Maria Lúcia Cacciola. São Paulo: Martins Fontes, 1995. 